American Journal of Pharmaceutical Education 2019; 83 (7) Article 7023.

\title{
RESEARCH
}

\section{Influence of the Fear of Missing Out in Student Pharmacists' Decision to Pursue Residency Training}

\author{
Ashley S. Crumby, PharmD, PhD, ${ }^{\mathrm{a}}$ Alicia S. Bouldin, PhD, ${ }^{\mathrm{a}, \mathrm{b}}$ Meagen M. Rosenthal, PhD, ${ }^{\mathrm{a}}$ \\ John P. Bentley, PhD, ${ }^{a}$ David F. Gregory, PharmD ${ }^{\mathrm{c}}$ \\ ${ }^{\text {a }}$ University of Mississippi School of Pharmacy, Oxford, Mississippi \\ ${ }^{\mathrm{b}}$ Editorial Board Member, American Journal of Pharmaceutical Education, Arlington, Virginia \\ ${ }^{\mathrm{c}}$ Belmont University College of Pharmacy, Nashville, Tennessee
}

Submitted February 15, 2018; accepted June 28, 2018; published September 2019.

Objective. To examine the influence of the fear of missing out (FOMO) on student pharmacists' postgraduate career decisions, specifically on whether to pursue a residency.

Methods. A 14-item FOMO scale was designed to examine the influence of this factor on student pharmacists' residency decision. A survey was distributed to second-, third-, and fourth-year student pharmacists at four participating universities. Average FOMO scores were compared based on residency intentions. Logistic regression analysis was used to predict residency intentions based on students' average FOMO scores.

Results. The survey response rate was $74 \%$. Of the 833 respondents, $42 \%$ indicated an intention to pursue residency training. Students indicated the FOMO items were "slightly" true of them, as evidenced by the overall FOMO mean score of 2.0 on a 5-point scale. Comparison among classes revealed a higher mean FOMO score among students in the second year of the pharmacy curriculum than among students in the third and fourth years. Logistic regression analysis indicated that FOMO score can reliably distinguish between students with residency intentions and those without.

Conclusion. This study supports the existence of FOMO in the decision to pursue a pharmacy residency, although more research and scale refinement is needed to better identify its impact.

Keywords: pharmacy residency, postgraduate career decisions, fear of missing out, student pharmacists

\section{INTRODUCTION}

For student pharmacists in their final year of the Doctor of Pharmacy (PharmD) program, the choice of a postgraduate path can be daunting and influenced by a variety of factors. There are several options available to these students; however, pharmacy residencies are becoming among the most popular. ${ }^{1}$ According to the professional vision of both the American College of Clinical Pharmacy (ACCP) and the American Society of HealthSystem Pharmacists (ASHP), having completed a pharmacy residency could be a requirement by 2020 for a pharmacist to provide direct patient care, although it is unknown at this time if this plan will come to fruition. ${ }^{2,3}$ Over the past several years, interest and demand for pharmacy residency positions has increased. In 2010, the number of students who participated in the ASHP Match was

Corresponding Author: Ashley S. Crumby, University of Mississippi School of Pharmacy, Faser 219B, PO Box 1848, University, MS 38677. Tel: 931-842-0080. E-mail:

ajstubbl@olemiss.edu
2,915 of the 11,487 PharmD graduates (approximately $25 \%)^{4,5}$ In comparison, 2016 statistics showed that 4,864 of the 14,556 graduating PharmD students (approximately $33 \%$ ) participated in the postgraduate pharmacy residency match process. ${ }^{6,7}$

When considering the motivators and barriers associated with the decision to pursue a residency, several have been identified as being influential in the process. ${ }^{8,9}$ Identified motivators include the desire to gain additional knowledge and experience or to pursue specialized training, and wanting to pursue a specific career path that requires residency training. ${ }^{8,9}$ Identified barriers to pursuing a residency include financial obligations, already having a job lined up after graduation that does not require completing a residency, and too much competition for pharmacy residency positions. ${ }^{8,9}$

Although past research has done well to identify these factors, there may still be other factors that could influence the decision to pursue a pharmacy residency. ${ }^{8-10}$ One such factor is a phenomenon called "fear of missing out." Fear of missing out (FOMO) is defined as "a 


\section{American Journal of Pharmaceutical Education 2019; 83 (7) Article 7023.}

pervasive apprehension that others might be having rewarding experiences from which one is absent" and is often characterized by "the desire to stay continually connected with what others are doing." "11 Students who have experienced FOMO often feel uneasy about missing out on positive experiences others may be having. ${ }^{11}$

To date, the majority of research examining the FOMO phenomenon is reported in the social media literature and focuses on its influence on social media use and how teenagers are constantly barraged by what their friends are doing. ${ }^{11}$ The concept of FOMO has not been applied in a professional setting, particularly in pharmacy education and career decision making. This study aimed to not only validate the existence of FOMO among student pharmacists, but to also identify its potential impact on students' postgraduate career choice.

\section{METHODS}

This study was a multicenter, cross-sectional, mixedmode survey of student pharmacists, and was a component of a larger study focused on the student pharmacists' decision-making process about the pursuit of residency training. Survey distribution took place at four institutions with various campus structures including a public university with a split campus (The University of Mississippi School of Pharmacy), a public university medical center campus (Northeast Ohio Medical University College of Pharmacy), a private liberal arts campus with a 0-6 year program (Butler University College of Pharmacy and Health Sciences), and a private liberal arts campus with a more traditional admittance structure (Lipscomb University College of Pharmacy). These institutions were chosen as a convenience sample that represented a wide variety of types of accredited pharmacy programs and was based on the principal investigator's professional relationships with contacts at each school. The study was approved as exempt by the Institutional Review Board (IRB) at the University of Mississippi, the main study site. The IRBs at each of the three other study sites were consulted and appropriate institutional policies were followed to allow them to participate in the study.

The survey instrument included questions about demographics, social media use, exposure to postgraduate pharmacy career options, and postgraduate plans. At the time of survey completion, students were asked to identify their intention to pursue or not pursue a pharmacy residency using a dichotomous response option (ie, yes/no). Students who were unsure of their intentions were instructed to choose "no" and were evaluated accordingly.

The survey instrument also included a scale designed to measure FOMO among student pharmacists. This scale was developed using items from a previously validated
FOMO scale by Przybylski and colleagues that was used in evaluating social media engagement. ${ }^{11}$ Using an iterative process, the researchers had developed a 10-item, unidimensional scale designed to measure FOMO with respect to peoples' general experiences. We adapted those general items from the Przybylski and colleagues scale to fit the context of postgraduate careers in pharmacy, specifically the pursuit of a pharmacy residency. The final scale included 14 items intended to measure FoMO among student pharmacists. Students were asked to rate each FOMO item using a 5-point response format on which $1=$ not at all true of me and $5=$ extremely true of me (the same response format used by Przybylski and colleagues). ${ }^{11}$

Prior to survey distribution, face and content validity were evaluated by pretesting the instrument among a focus group of past residents and faculty members familiar with the residency application process. Because of the mixed-mode approach used for this study, pretesting was conducted for both the paper and electronic versions of the instrument. All constructive comments were incorporated into the final survey version.

The survey was administered in March 2016 via a mixed-mode design to students in their second, third, and fourth professional years of the pharmacy curriculum at their respective institutions. A paper survey instrument was distributed during a single class period to secondand third-year students by a research colleague at each participating institution, and responses were collected immediately following completion. Because of the difficulty in distributing paper-based survey instruments to students completing advanced pharmacy practice experiences, fourth-year students were asked to complete an electronic version online via Qualtrics survey software (Qualtrics, Provo, UT). The online survey was active for two weeks, and all potential respondents received an email reminder regarding participation approximately one week after the initial invitation was sent. First-year students were excluded from this evaluation because most had likely not considered postgraduate plans yet. Student participation was voluntary, but as an incentive, all respondents were included in a drawing for one of two $\$ 100$ gift cards.

Data analysis was conducted using SPSS for Windows, Version 22 (IBM Corp., Armonk, NY). Descriptive statistics were used to evaluate demographic data including gender, mean age, ethnicity, year in school, type of institution attended, and postgraduate career plans. For the FOMO scale, reliability was determined using Cronbach alpha. As done by Przybylski and colleagues, FOMO scores were computed for each student by calculating an average across all 14 items, and these scores were compared between students with residency intentions and those 


\section{American Journal of Pharmaceutical Education 2019; 83 (7) Article 7023.}

without using an independent $t$ test. To evaluate FOMO differences between second-year (P2), third-year (P3), and fourth-year (P4) classes, ANOVA was used to detect an overall difference, and Tukey HSD was used post-hoc to conduct pairwise comparisons. The impact of FOMO on the decision to pursue a residency was evaluated using logistic regression.

\section{RESULTS}

A total of 1,130 survey instruments were distributed, and 870 (77\%) were completed, including 652 paper survey instruments and 218 electronic survey instruments. Of the 870 completed survey instruments, 833 were deemed usable. Response rates from each of the four participating institutions varied from $62 \%(n=199$ of 322$)$ to $83 \%$ $(n=185$ of 223$)$, with an overall response rate of $74 \%$.

Collective demographic characteristics can be found in Table 1. The responding sample can be characterized as mostly female (66\%) and white/Caucasian (85\%), and

Table 1. Demographic Information for Student Pharmacists Responding to a Survey to Determine the Influence of FOMO in Their Decision of Whether to Pursue a Residency $(\mathrm{N}=833)$

\begin{tabular}{lc}
\hline Variable & No. $\mathbf{( \% )} \mathbf{q}^{\mathbf{a}}$ \\
\hline Gender & $281(34.2)$ \\
Male & $540(65.8)$ \\
Female & \\
Age & $649(78.4)$ \\
$21-25$ & $138(16.7)$ \\
$26-30$ & $29(3.5)$ \\
$31-35$ & $12(1.4)$ \\
36 years or older & \\
Ethnicity & $706(85.4)$ \\
White/Caucasian & $22(2.7)$ \\
Black/African American & $5(0.6)$ \\
Hispanic/Latino & $2(0.2)$ \\
Native American/American Indian & $67(8.1)$ \\
Asian/Pacific Islander & $25(3.0)$ \\
Other & \\
Year in School & $352(42.3)$ \\
P2 & $299(35.9)$ \\
P3 & $182(21.8)$ \\
P4 & \\
Institution & $199(23.9)$ \\
University of Mississippi & $155(18.6)$ \\
Lipscomb University & $185(22.2)$ \\
Northeast Ohio Medical University & $294(35.3)$ \\
Butler University & \\
Intention to Pursue Residency & \\
Training (n=833) & $353(42.4)$ \\
Yes & $480(57.6)$ \\
No & \\
\hline Abbien &
\end{tabular}

Abbreviations: $\mathrm{FOMO}=$ fear of missing out

${ }^{a}$ Number may be different from 833 due to missing data was consistent across all four sites. The average student age among the sites ranged from 23 to 26 years old, with an overall average age of 24 years. Of the three classes of students included in the study, the P2 students comprised the highest proportion of respondents. The distribution of respondents among campus types was similar. When evaluating postgraduate plans at the time of survey administration, 353 students (42\%) indicated they planned to pursue a pharmacy residency upon completion of the PharmD program while 480 students $(58 \%)$ did not intend to complete a residency after graduation.

The FOMO instrument demonstrated acceptable reliability in our sample with a Cronbach alpha of 0.88 . The overall FOMO mean score was $2.0(\mathrm{SD}=0.7$ on a 5 -point scale, indicating that on average, students felt that the items related to FOMO in the context of this study were "slightly true" of them. The scores on these items ranged from 1 to 4.4. When grouped based on the midpoint score of $3,88 \%$ of the FOMO scores were below the midpoint, with 729 of respondents rating the item less than 3 and 101 respondents rating the item greater than 3 . The item with the highest rating was related to the importance of understanding all potential residency options available in order to be competitive. Other items receiving higher ratings included topics such as involvement during pharmacy school and grades. The item with the lowest rating was related to the importance of sharing good things that happen on social media as they relate to a future residency. Information regarding each item can be found in Table 2 .

Mean FOMO scores were compared between students in different years of the professional pharmacy curriculum. Overall, a significant difference was seen when comparing the mean FOMO scores among students in the different professional years $(\mathrm{F}=10.4, p<.001)$. Pairwise comparisons indicated a higher mean score for secondyear students (2.1) as compared to third-year (2.0) and fourth-year students (1.8). No significant difference was seen between scores of third- and fourth-year students.

Logistic regression analysis was conducted to predict student pharmacists' intention to complete a residency using FOMO score as the predictor variable. A test of the regression model that included the predictor variable was significant, indicating that the FOMO score could reliably distinguish between those students who intended to pursue a residency and those who did not (chi square $=87.6, p=.001$ with $\mathrm{df}=1$ ). The model had a Nagelkerke $\mathrm{R}^{2}$ of .13 with a classification accuracy of $63 \%$ (39\% for those with residency intentions and $81 \%$ for those who did not intend to pursue a residency) and a cstatistic of .689, indicating acceptable discrimination. An odds ratio of 2.6 for the FOMO variable $(95 \% \mathrm{CI}=2.1$, 


\section{American Journal of Pharmaceutical Education 2019; 83 (7) Article 7023.}

Table 2. Scores of Student Pharmacists Responding to a Survey to Determine the Influence of FOMO in Their Decision of Whether to Pursue a Residency $(\mathrm{N}=833)^{\mathrm{a}, \mathrm{b}}$

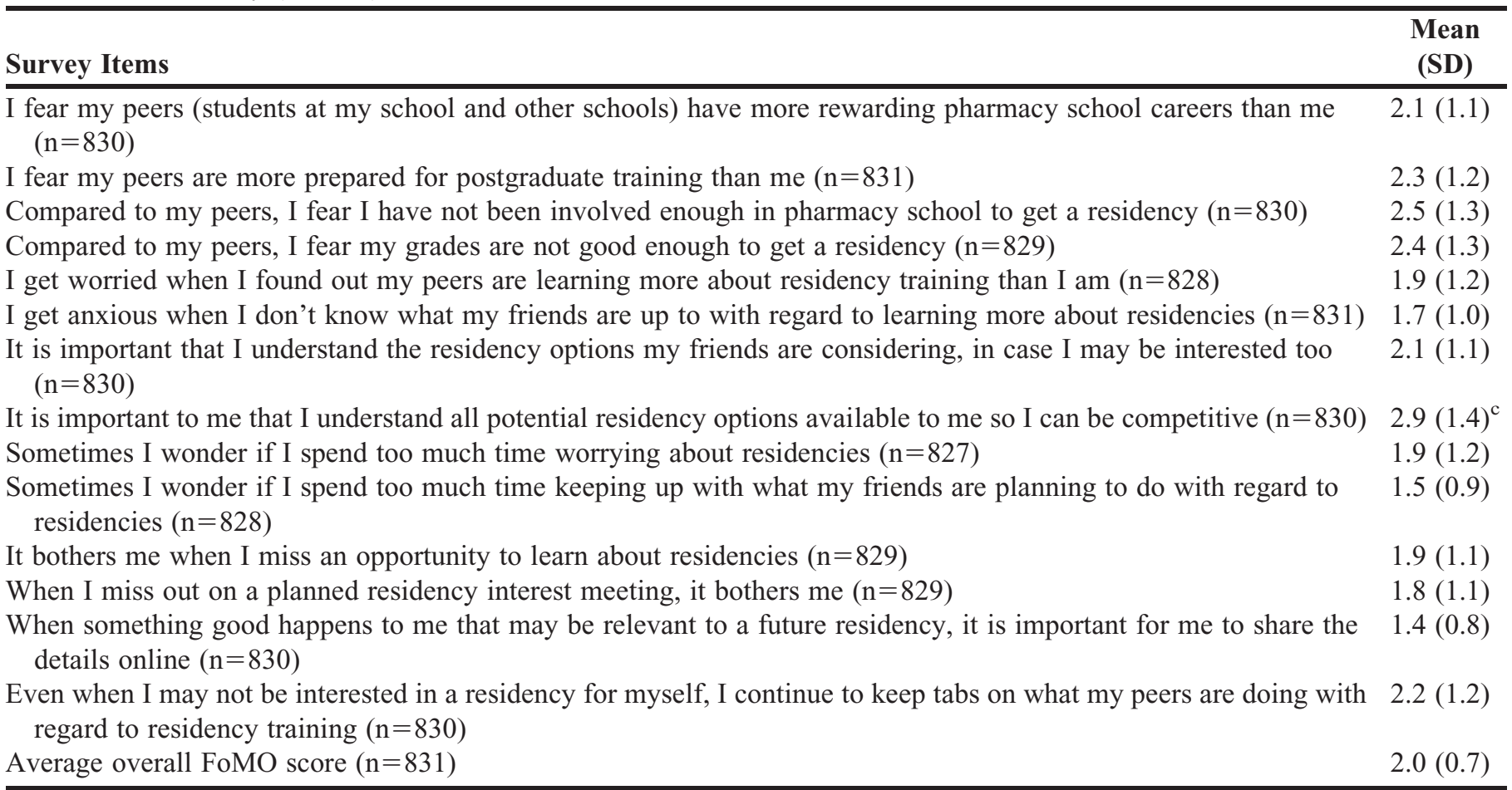

${ }^{a}$ Survey instrument adapted from that created by Przybylski and colleagues ${ }^{11}$

${ }^{\mathrm{b}}$ A 5-point scale on which $1=$ not at all true of me and $5=$ extremely true of me was used for survey responses

${ }^{\mathrm{c}}$ Highest mean FOMO score in the set

3.3) indicates that for a 1-point increase in FOMO score, the odds of a student intending to pursue a residency increases by a factor of 2.6. The relationship between FOMO and intention to pursue a residency remained significant $(\mathrm{OR}=2.9,95 \% \mathrm{CI}=2.3,3.7)$ even after adjusting for sex, age, and social media use and dummy-coded variables representing year in school and the different data collection sites. An interaction between FOMO score and year in school was added to a subsequent logistic regression model to evaluate whether the relationship between FOMO and intention to pursue a residency was different between P2, P3, and P4 students. The overall test of the interaction was not significant $(p=.16)$, suggesting that the effect of FOMO on intentions was not dependent on year in school.

\section{DISCUSSION}

For this study, approximately $40 \%$ of responding students indicated an intention to pursue a residency upon graduation from pharmacy school. This percentage is slightly higher than that reported in a graduating student survey conducted by the American Association of Colleges of Pharmacy (AACP) in which $29 \%$ of students indicated residency intentions. ${ }^{1}$ In the study population, the percentage of responding students indicating an intention to pursue residency was highest among third-year students and lowest among students in their final year, while the percentages of final year and second-year students were similar $(\mathrm{P} 2=55.4 \%, \mathrm{P} 3=61.9 \%, \mathrm{P} 4=55.0 \%)$. One explanation for this difference could be that students in their third year of the curriculum have given more thought to their postgraduate plans compared to second-year students, but are not yet at the point where they need to make a definitive decision like students in their final year. The choice of postgraduate path is more hypothetical to students who are in earlier stages of the curriculum, at which point they have not had much practical pharmacy exposure through introductory or advanced pharmacy practice experiences. For students in the final year of the professional curriculum, the postgraduate decision is imminent, and their intentions are more likely to result in action as compared to students earlier in the curriculum.

In past work, factors thought to influence the decision to pursue a pharmacy residency have been investigated. ${ }^{8,9}$ Among these are factors such as the desire to gain more knowledge, experience, and specialized training, which are considered motivators in the decision to pursue pharmacy residency training. ${ }^{8,9}$ Financial obligations and a highly competitive process for obtaining a postgraduate training position are both potential barriers 


\section{American Journal of Pharmaceutical Education 2019; 83 (7) Article 7023.}

that may hold students back from applying to pharmacy residencies. $^{8,9}$

In addition to these factors, prediction of residency intention using the theory of planned behavior has been studied. ${ }^{10}$ In this work, an extended model was used to measure the attitude, subjective norms, and perceived behavioral control, and all were found to be significant predictors of intention to apply to a pharmacy residency program. ${ }^{10}$ Other significant predictors included the belief that a pharmacy residency would not only lead to an increase in confidence while practicing pharmacy, but that it would aid in the attainment of future career goals. Influences from faculty members as well as family members were also found to be significant predictors of students' intention to pursue residency training. When considering factors that may make it more difficult to apply for a pharmacy residency, financial obligations, the fear of competition or possibility of not matching with a program, finding the application and/or interview process to be too long, and the need for possible relocation based on where the residency program is located were all found to be significant predictors of perceived behavioral control with regard to residencies. ${ }^{10}$

Although not explicitly investigated prior to this study, FOMO may be a potential contributor to the decision to pursue a pharmacy residency. The average FOMO score identified in this study was 2.0 on a 5-point scale. This may seem somewhat low given the prevalence of FOMO indicated by the preliminary qualitative interviews, but that average is similar to those identified in previous research in the area of social media use and with different samples (average scores of 1.9, 2.4, and 2.6). ${ }^{11}$ The seemingly low FOMO score could have been the result of a self-report bias among the student pharmacists in our study. Although the respondents may have recognized that FOMO existed on a more global level, it may have been difficult to identify it in their own life. Even if the phenomenon is recognized, measuring it may prove difficult in this population. Another possible explanation for the average FOMO score being somewhat lower than expected could be the influence of respondent social desirability bias. ${ }^{12}$ Because negative connotations may be associated with the idea of FOMO, some students may have answered the survey questions in a way they thought would be more socially acceptable. ${ }^{12}$

The item, "It is important to me that I understand all potential residency options available to me so I can be competitive," received a mean score of 2.9 on the 5point scale. This score is somewhat higher relative to FOMO scores on other items and helps support the argument that these students were well aware of the competitive nature of the residency process and felt some element of pressure to be "in the know" regarding what was available.

Another item that received a comparatively higher score was, "Compared to my peers, I fear I have not been involved enough in pharmacy school to get a residency." This item may have received a higher score for a few reasons. First, the high score suggests that students recognized that preparing themselves to be competitive compared to their peers was important in the residency search and application process. Also, students may have believed that a "standard" existed to which they were comparing themselves and others. Students may have perceived there was a specific level for what was "enough" involvement to be considered for a residency position.

Finally, the item "Compared to my peers, I fear my grades are not good enough to get a residency," was scored similarly to the previously mentioned items and again identified a competitive nature with peers in addition to self-imposed expectations for grades. Past research has also identified the perception of importance of grades among students when considering residency programs. ${ }^{8,9}$ This may cause some students to place a great deal of emphasis on grades, but fail to realize that programs are also looking for well-rounded candidates. Many programs seek candidates who not only performed well in the classroom but also took time to invest in the profession and their own professional development. ${ }^{13}$

The FOMO scores were compared between P2, P3, and $\mathrm{P} 4$ students, and mean differences were found among students at different stages of the pharmacy curriculum. Students in the second year of the professional program identified a greater level of FOMO about career choice than students in their third and fourth years. One possible explanation for this change in FOMO scores could be that students in the later years of their pharmacy education experience may be less influenced by what others are doing because they have invested more personal thought into their own postgraduate plans. Students in their second year may be more influenced by others and may "go with the crowd" because they do not have a clear idea of their own plans. Additionally, students in their second year may also be less knowledgeable with regard to postgraduate career options, resulting in more comparison with others who seem to be relatively more knowledgeable about postgraduate options.

This study showed a small Nagelkerke's $\mathrm{R}^{2}(.13)$ when attempting to predict residency intentions by only average FOMO score, meaning that $13 \%$ of the variance when evaluating this intention can be explained by FOMO alone. This is not surprising as it was never expected that this relatively new phenomenon would explain a great deal of the decision-making process among 


\section{American Journal of Pharmaceutical Education 2019; 83 (7) Article 7023.}

student pharmacists considering residency training. However, we anticipated that FOMO would be present and would contribute on some level to the decision to pursue a residency, a result that is supported by our study results. The odds ratio for FOMO in this study indicates a relationship where an increase in FOMO score increases the odds of a student intending to pursue a residency position, supporting the contribution of the phenomenon.

This research was not without its limitations. As might be expected, the response rate for the online survey was lower compared to that for the paper version. There are several possible explanations for this. The online survey was completed only by students in their final year of the program who were completing clinical rotations and may have opened the email and subsequently chosen not to participate or forgot to complete the survey later. Also, the online survey could have been completed over a twoweek timeframe whereas the paper survey was completed all in one sitting at one specific time. Finally, the email containing the survey may have gone unchecked, which may have prevented students from being presented with the opportunity to participate.

Other limitations existed with the FOMO scale itself. To date, the only other research in which a FOMO measure was applied was in the computer sciences where researchers used this construct to understand social media engagement. ${ }^{11}$ These authors focused on a general experiences-based FOMO construct rather than one tailored to a specific domain, such as career aspirations. The adaptations made to that scale for this study allowed for its application in a pharmacy setting regarding postgraduate career choice. Because of the overall novelty of the phenomenon and the scale in general, particularly in pharmacy career pursuit, limitations may exist with its use and will only be overcome by repeated use, testing, and refinement of the instrument. Another potential limitation with the scale is the terminology used with the items. Even though an operational definition of fear was provided in the survey instrument, the word has multiple connotations. Interpretation of the word fear as used in some of the items in this scale could have influenced the way in which students responded. For example, students may have a fear of something that makes them avoid it. In the context of FOMO, associating the word "fear" with avoidance would not apply. Also, the word fear connotes something that students may not be willing to admit or even recognize in their own experiences, and this may have limited how they identified with the scale items. This may have caused students to misinterpret the scale items and potentially downplay the impact of FOMO in their lives.
Another potential limitation and explanation for a lower FOMO score could be the wording of the items on the scale itself. Although all students completed the FOMO scale, the items included residency specific language, which may be more difficult to interpret for students not intending to pursue that postgraduate path.

Future areas of research should include revision and refinement of the FOMO instrument by including more items that directly relate to comparison with others and the apprehension that is involved in that comparison. The current items could be revised to better reflect the comparative nature of FOMO and doing so may result in a clearer identification of the phenomenon among student pharmacists. Another potential interesting area for further research includes grades and students' personal expectations for academic performance with regard to residencies versus the expectations of the programs themselves. Finally, the distribution of FOMO scores in the present study suggests the possibility of different classes of students with respect to their responses to the FOMO items. Thus, future research should explore the presence and meaning of these potential unknown populations (ie, latent classes). ${ }^{14,15} \mathrm{Al}$ though the overall FOMO mean score was somewhat low, there may be meaningful subgroups of students who have significant FOMO with respect to residency training.

\section{CONCLUSION}

The concept of FOMO is common among college students in their everyday lives, but formal studies evaluating this phenomenon are lacking. This study is the first known attempt at identifying and analyzing the FOMO concept in student pharmacists' career decision-making process and adds to the literature surrounding factors that influence the decision to pursue a pharmacy residency. Although residency training is valuable and provides many opportunities for attainment of skills, ${ }^{16}$ this may not be the right option for every student. The results of this study can be used by pharmacy educators to better mentor and advise students about their postgraduate options. The evaluation of FOMO could serve as a valuable tool in identifying motives behind pursuing a residency position and could help pinpoint whether a student is truly interested in the opportunity or if the residency interest is based on fear of missing out on an opportunity that others are taking advantage of. By helping students identify the reasoning behind their decisions, educators may be more able to guide them down the path that is best suited to their strengths and career interests. Once the motives or reasoning behind the desire to pursue a path have been 


\section{American Journal of Pharmaceutical Education 2019; 83 (7) Article 7023.}

identified, a more student-centered career planning approach could be used.

\section{ACKNOWLEDGMENTS}

The authors wish to thank Timothy Ulbrich, PharmD, from Northeast Ohio Medical University, Chad Knoderer, PharmD, from Butler University, and Sarah Uroza, PharmD, from Lipscomb University, for their collaboration and encouragement with this study.

\section{REFERENCES}

1. American Association of Colleges of Pharmacy Graduating Student Survey: 2017 Public School Summary Report. https:// www.aacp.org/sites/default/files/2017-10/2017_GSS_Public\% 20School\%20Summary\%20Report.pdf. Accessed May 9, 2018. 2. Murphy JE, Nappi JM, Bosso JA, et al. American College of Clinical Pharmacy's vision of the future: postgraduate pharmacy residency training as a prerequisite for direct patient care practice. Pharmacotherapy. 2006;26(5):722-733.

3. Johnson TJ. Pharmacist work force in 2020: Implications of requiring residency training for practice. Am J Health Syst Pharm. 2008;65(2):166-170.

4. Bright DR, Adams AJ, Ulbrich TR, Soric MM. Mentoring residency candidates: avoiding misinformation and employing best practices. Innov Pharm. 2015;6(2).

5. 2014-15 Profile of Pharmacy Students, American Association of Colleges of Pharmacy. https://www.aacp.org/sites/default/files/201710/Degrees\%20Conferred.pdf. Accessed May 9, 2018.

6. 2015-16 Profile of Pharmacy Students, American Association of Colleges of Pharmacy. https://www.aacp.org/sites/default/files/201710/PPS_2016_DegsConf.pdf. Accessed May 9, 2018.
7. Summary Results of the Match for Positions Beginning in 2016, American Society for Health-System Pharmacists. https:// natmatch.com/ashprmp/stats/2016applstats.pdf. Accessed May 9, 2018.

8. McCarthy BC, Weber LM. Update on factors motivating pharmacy students to pursue residency and fellowship training. Am J Health-Syst Pharm. 2013;70(16):1397-1403.

9. Hammond DA, Oyler DR, Devlin JW, et al. Perceived motivating factors and barriers for the completion of postgraduate training among American pharmacy students prior to beginning advanced pharmacy practice experiences. Am J Pharm Educ. 2017;81(5):Article 90.

10. Hickerson SC, Fleming ML, Sawant RV, Ordonez ND, Sansgiry SS. Predicting pharmacy students' intention to apply for a residency: a systematic theory of planned behavior approach. Curr Pharm Teach Learn. 2017;9(1):12-19.

11. Przybylski AK, Murayama K, DeHaan CR, Gladwell V. Motivational, emotional, and behavioral correlates of fear of missing out. Comput Hum Behav. 2013;29(4):1841-1848.

12. Singleton R, Straits BC. Approaches to Social Research. 5th ed. New York: Oxford University Press; 2010.

13. Gohlke AL, Ray DB, El-Ibiary SY, Barletta JF. Characteristics of the ideal postgraduate year 1 pharmacy practice residency candidate: a survey of residency program directors. $J$ Pharm Pract. 2014;27(1):84-88.

14. Collins LM, Lanza ST. Latent Class and Latent Transition Analysis: With Applications in the Social Behavioral, and Health Sciences. Hoboken, N.J: Wiley; 2010.

15. Geiser C. Data Analysis with Mplus. New York: The Guilford Press; 2013.

16. McElhaney A, Weber RJ. Role of pharmacy residency training in career planning: a student's perspective. Hosp Pharm.

2014;49(11):1074-1080. 